\title{
Teaching Professional Vocabulary to the Students in Coal Region Universities through Digital Educational Tools
}

\author{
Alena Perevalova ${ }^{1}$, Anna Resenchuk $^{1}$, and Nina Tunyova ${ }^{1, *}$ \\ ${ }^{1}$ Kemerovo State University, Institute of Philology, Foreign Languages and Media communication, \\ Department of Foreign Languages, 650000, 6 Krasnaya st., Kemerovo, Russia
}

\begin{abstract}
This paper discusses the approach to teach professional vocabulary to mining students with the emphasis on digital educational tools and e-learning. A digital educational tool is considered to be a web service or application that can be used to create and enhance a digital learning environment. The paper deals with incorporating to the educational process such web-services as Quizlet, Learning Apps, Wiser.me, WordSift, which help the students build and enlarge professional vocabulary that is necessary to read and analyze scientific articles, to operate it in future professional activity while communicating and collaborating with foreign colleagues. The article touches upon the main advantages of used digital educational tools, which allowed the students to obtain translating, reading and analytical skills. The article notes that acquired knowledge and skills will make the students able to work successfully in the mining industry sharing experience and cooperating with international partners. Kuzbass (Kemerovo region) is one of the largest coal deposits in the world, located in the south of Western Siberia. Region has significant experience in training compatriot specialists and international students in geology, mining industry, ecology and nature management. Every year students from neighboring countries come to our universities to receive a prestigious profession in the mining sector. Future highly qualified specialists should not only master the production process, but also be able to share experience and communicate with foreign colleagues. The result of mastering professional English and special vocabulary will be the possibility of doing business and research at the international level with the countries, leading in coal mining.
\end{abstract}

\section{Introduction}

Expanding international cooperation in coal industry requires a future specialist to an active use of a foreign language. A large number of studies in the field of coal mining are conducted and published by foreign scientists. A highly qualified specialist needs to learn how to work with English professional vocabulary to read and understand the scientific publications describing the results of experimental studies. The articles in the field of mining are

\footnotetext{
${ }^{*}$ Corresponding author: ninatunyova@yandex.ru
} 
scientific publications describing the results of experimental studies and formatted according to the technical requirements of the journals included in these databases. Articles are presented in a strict, scientific style, coherent and logical. Forms, meanings and usages are involved in a vocabulary knowing [1]. Teaching professional vocabulary to the Russian and international students in coal region universities is the key to understanding highly rated scientific articles (Scopus and WoS).

Apart from Russian students, many international students from 24 countries are provided undergraduate and postgraduate education at the universities of Kuzbass [2]. Groups of students can be either mono-ethnic (Russian students) or multinational (the group includes students from Russia, Uzbekistan and Kyrgyzstan).

Nowadays we are currently living in the digital era, which spreads through various areas, including education. Modern educational standards demand around three quarters of classroom activities should be provided interactively, including interactive worksheets, online tests, simulation games, e-learning environment etc. [3]. Following these requirements allows students to increase learning motivation, ensure high learning outcomes. Nowadays some researchers start formulating concepts and teaching methods of scientific translation in e-learning environment [4]. It allows to organize and individualize studying process, create and develop self-education, which is highly topical due to classroom hours cut and self-study rise.

We supposed digital educational tools could ensure high learning outcomes in the view of class-room hours reduction and rise of self-study work. Moreover, these tools can complement and support traditional learning methods. We developed a set of interactive tasks, quizzes, mid-term and final tests, polls, using various web-services, and integrated them in the ESP education process.

In today's 21 st century classrooms, digital educational tools must coexist alongside with traditional tools. Online tools, compared to their traditional counterparts, provide a broader array of information about words and word meanings. In addition, some tools allow teachers to easily customize words so that students can practice, review, and play games with content or unit-specific words.

Digital educational tools have advantages. For example, many of them allow students: listen to pronunciation, view photos and images related to words, reinforce word learning through interactive games, manage classroom, encourage collaboration with classmates, facilitate online practice etc.

\section{Materials and methods}

At present time there are numerous web-services which can be applied to enlarge professional vocabulary (Quizlet, Learning Apps, Classtime, H5P, etc.). Some of them have been successfully integrated by us in ESP teaching and we are ready to share our experimental results. The following digital educational tools show promise to support word learning, review, and playing with language. We have grouped these tools into three categories: Word clouds, Games and Review tools, and Voting tools.

An example of a word cloud generator we used was WordSift. It was created to help quickly identify important words that appear in a text. We could easily sift through the scientific papers, scrutinize them, and choose the professional vocabulary for study (words in a large font). Unlike other word cloud generating tools such as Wordle or TagCrowd, WordSift combines several features for vocabulary learners, including a tag cloud, word sorting, a visual thesaurus, links to Google images and videos, and example sentences. This free and interactive vocabulary learning website works with most web browsers and requires minimum computing knowledge and zero plugins. According to WordSift.org, this website is especially suitable for intermediate-level English language learners who have 
difficulty in advancing their proficiency level due to limited vocabulary knowledge in academic content areas. While it was primarily designed for the needs of English language learners in K-12 settings, it can also meet the needs of vocabulary learners in other settings (e.g., university). WordSift is a versatile tool that can easily fit into any lesson plans featuring explicit vocabulary instruction. It enables students meaningfully interact with the vocabulary that they encounter in academic texts. WordSift's main feature is the generation of a word cloud based on a user-selected text. A text can be copied and pasted into the box in the homepage, where a click on "Sift" then generates a word cloud showing the 50 most frequently occurring words in the text (function words are automatically excluded). The word cloud is illustrated in Fig. 1.

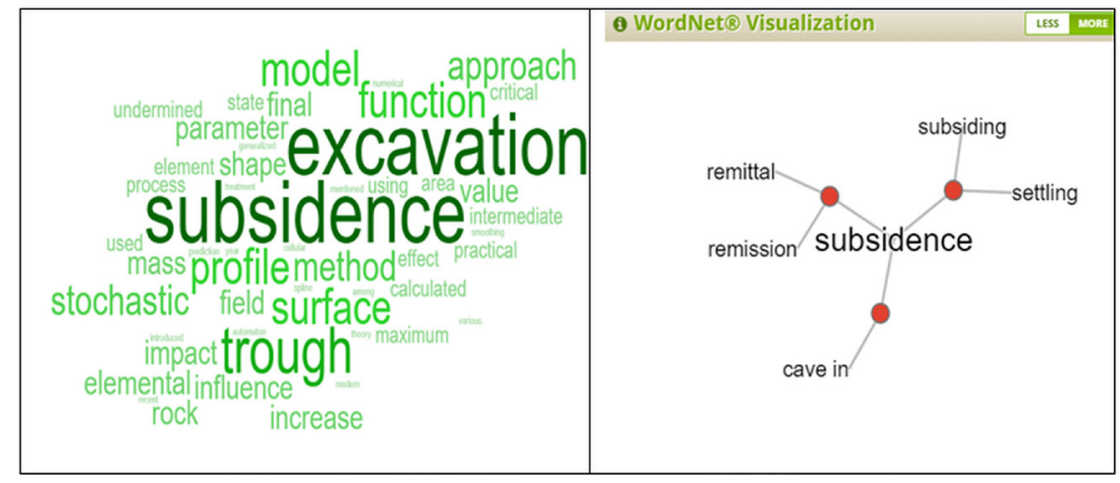

Fig. 1. General view of mining vocabulary tree.

A mobile and web-based study application Quizlet that allows students to study information through learning modes and games can be included into Games and Review tools. After we had formed the professional vocabulary list, we created a new study set using Quizlet. It should be noted that this application focuses on vocabulary, its enlargement but not on an in-depth study of the language. Quizlet's mission is to help students (and teachers) practice and master what they are learning. We suppose Quizlet being a great tool for students for some reasons. It can help students review in the way that works best for them, arrange collaboration and teamwork in class.

Quizlet has seven standard study modes that help students review in the way that works best for them.

Flashcards - A quick way to review terms and definitions, just like paper-based flashcards.

Learn - A personalized study mode based on how well you know information in a study set.

Write - A fill-in-the-blank style study tool.

Spell - A study mode that dictates a term or definition that you must correctly type.

Test - An easy way to quiz yourself on how well you know information in a study set.

Match - A time-based game where the student must match terms and definitions.

Gravity - A level-based game where the student must answer correctly.

Quizlet allows to acquire collaboration and teamwork skills, while helping students review. Quizlet Live is an in-class game that teachers can use to help students review information while working together in teams. The game randomly sorts students into teams to match terms and definitions, and the first team to correctly answer all questions wins. Quizlet Live is fully focused on accuracy over speed. If a team answers any question wrong, it has to start over from the beginning. This ensures students' competitive spirit will not override the need to answer correctly. 
Another Game and Review tool was Wizer. This service aims to create interactive worksheets by using different types of questions, incorporating images and videos, and even recording audio directions. Teachers can ask students to label images, categorize information, respond to open-ended and multiple-choice questions, or respond to video content. It can be used to flip the classroom by following videos with open response questions to be discussed in class. Teachers can create cloze reading passages to assess reading comprehension and vocabulary skills. A teacher has an opportunity to organize a collaborative work with help of this service. We used it as a supplement tool to build and enlarge students' professional vocabulary and as a formative assessment tool. A teacher can embed the link to his blog or site or share the link with students via email or social network.

Wizer.me can offer the following tasks: open question, multiple choice questions, fill in the blank, fill on an image, matching, draw, sorting and table, web tools - allows to load webpages, and YouTube videos into the worksheet. Multiple choice task is shown in Fig. 2.

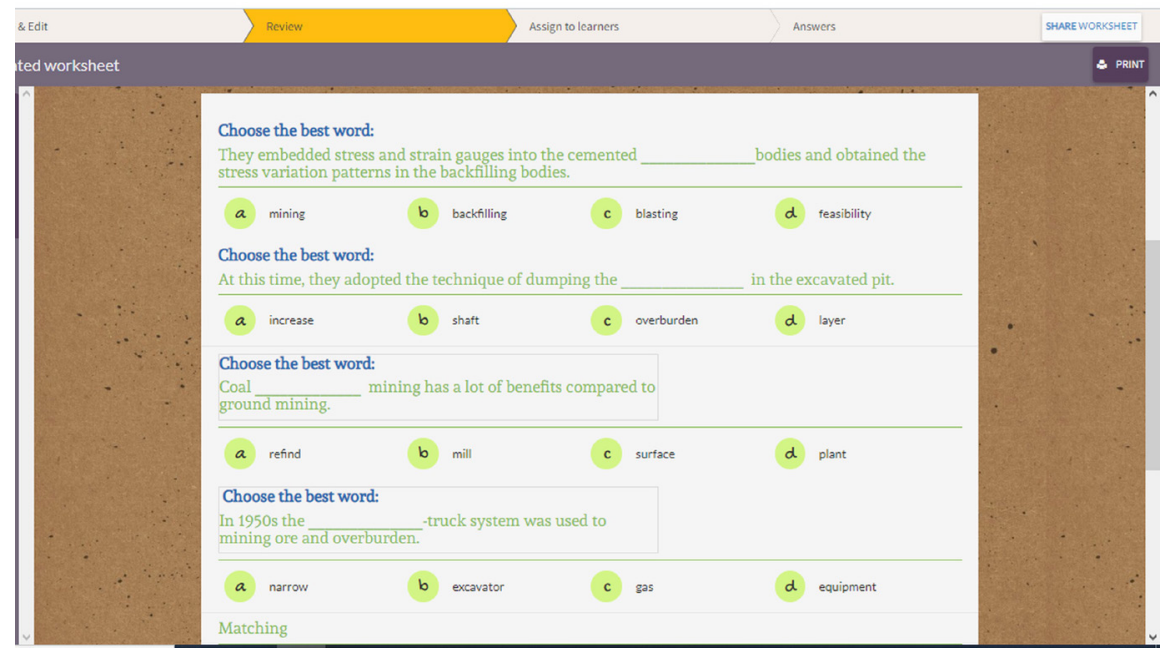

Fig. 2. Multiple choice task for mining students.

Matching task is shown in Fig. 3.

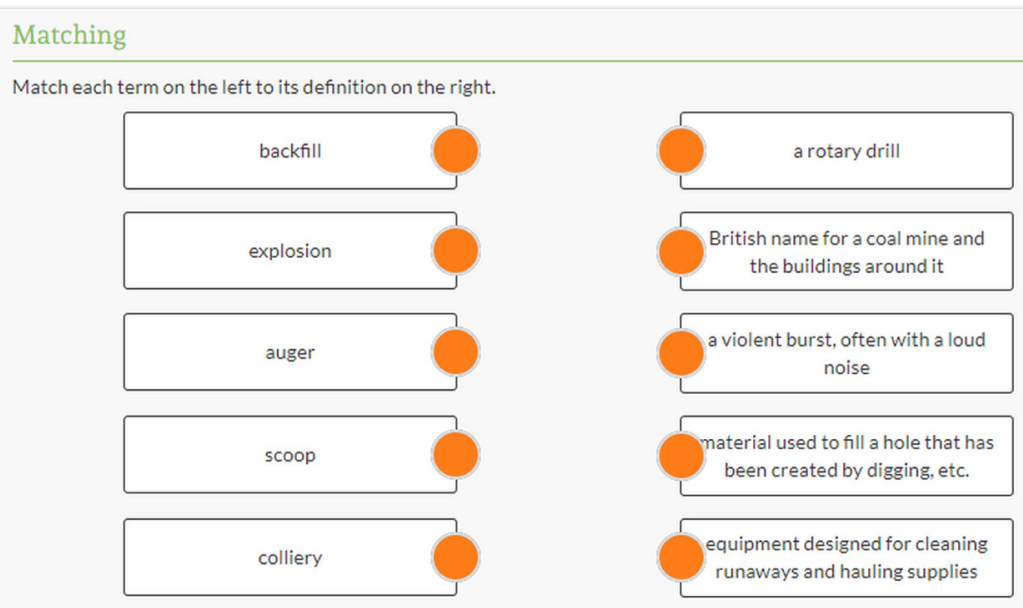

Fig. 3. Matching task for mining students. 
Besides, this service has a grading feature. It tells a teacher how long the students spent on the assignment, the grade, and even allows provide typed or audio feedback to the student.

LearningApps is one more Game and Review tool which resembles the previous one but has a unique feature (it can be embedded in any LMS as SCORM content). It is designed to support learning and teaching processes with small interactive modules. Those modules can be used directly in learning materials, but also for self-studying. The aim is to collect reusable building tasks and make them available to everyone. Tasks (called Apps) include no specific framework or a specific learning scenario. The tasks can be embedded in an appropriate teaching scenario.

Tasks offered by this app are: matching pairs, grouping, number line, simple order, free text input, matching pairs on images, multiple-choice quiz, close test, word grid, the millionaire game, word puzzles etc. Finding collocations task is illustrated in Fig. 4.

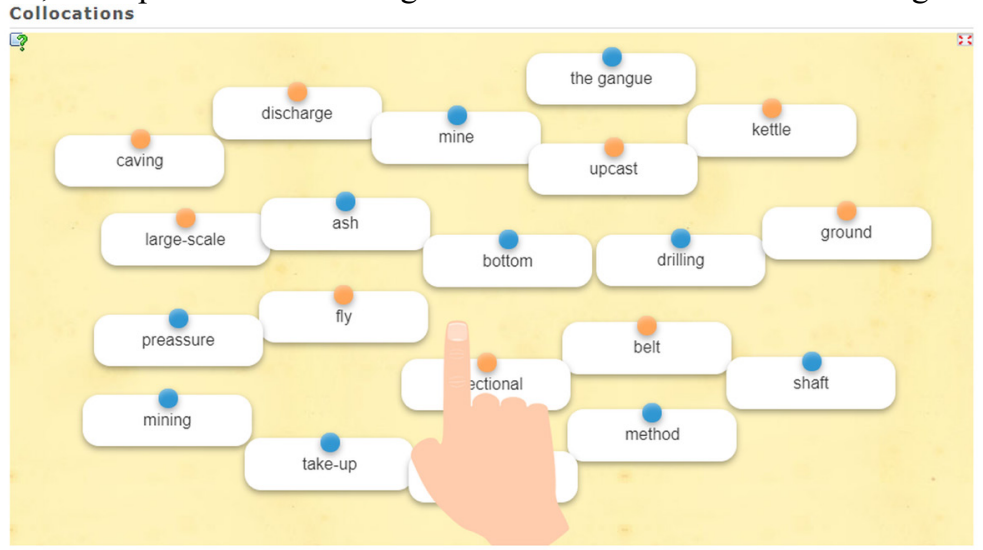

Fig. 4. Finding collocations task for miners.

Word search task is demonstrated in Fig. 5.

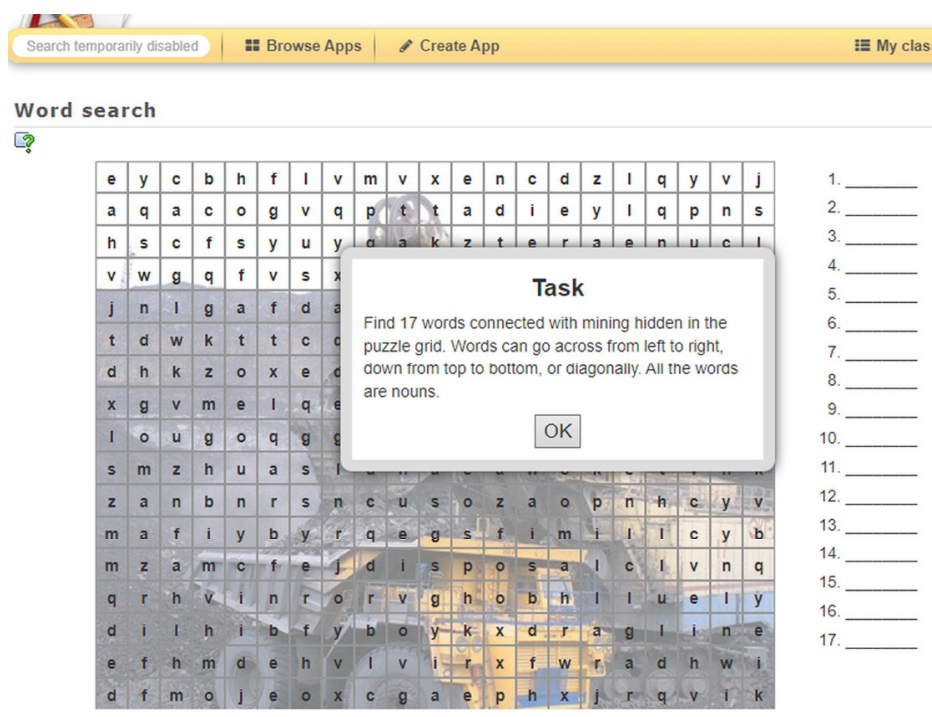

Fig. 5. Word search task for miners. 
This service allows a teacher to trace learning progress of a student.

One of the significant functions of many digital educational tools is an instant feedback [5]. Feedback is a vital part of formative assessment, which enhances a rise of students' motivation, giving them a possibility to evaluate and control learning by themselves [6]. Furthermore, this function allows a teacher instant detection of knowledge gaps [7], helps to reveal weak points of presenting learning material and correct teaching methods. A teacher can detect which language aspect or material requires extra clarification or larger number of exercises and prepare problem-solving tasks for post-test discussion. The teacher can create new interactive tasks, based on augmented reality and geolocation apps $[8,9]$. The digital tools, such as Kahoot!, Plickers, Socrative, Poll Everywhere, Easy Test Maker, My Quiz, which serve to ensure instant feedback, make the Voting tools category in our research and were described by us in detail in our previous research [10].

In 2018-2019 we conducted the experiment with 107 specialists for mining region learning ESP in Kemerovo State University. We divided them into 2 experimental groups (80 students) and 1 control group (27 students). According to the European language framework the language competence of all students ranged from A2 to B1. The experiment involved the summative and formative assessment stages. During the summative assessment we revealed a level of professional vocabulary among the experimental and control students. During the formative assessment we integrated the web-services into the ESP lessons to build a professional thesaurus among experimental students, made a comparative study of midterm and final students' learning outcomes in the experimental and control groups and revealed experimental students' attitude to the applied digital educational tools.

The professional vocabulary was taught in various ways in the experimental and control groups. We offered ESP lessons supported with digital educational tools for the experimental groups and traditional ESP lessons for the control group. Students of all groups were supposed to do similar learning activities to build professional thesaurus but presented either in an interactive or traditional way.

At the start of the experiment we extracted the professional terms from the scientific papers via the word cloud service Wordsift. Then the experimental students learnt these professional terms with help of the Quizlet service. As supplement tools they were offered to do interactive tasks created by us in Wizer.me and LearningApps services to practise vocabulary. Students were encouraged to work with these services both in the classroom and at home during out-of-class independent work. Instant feedback was ensured by Socrative and My quiz services. To assess their learning outcomes, we used interview method and tests.

At the summative assessment we tested the level of professional vocabulary among all students which showed the equal level among 2 experimental groups $(35 \%, 42 \%)$. The level of professional vocabulary among the control group was lower (30\%). During the academic year we taught web-services supported lessons of ESP (carried out ten classroom vocabulary tests, one midterm vocabulary test and one final vocabulary test) in three experimental groups. All tests included multiple choice questions and true/false statements. After each test post-test discussion was arranged to promote understanding of the studied issue. The control group students took part only in the midterm and final vocabulary test. All the tests were identical for all the students.

\section{Results and discussion}

At the formative assessment, we compared the average scores of all the vocabulary test in the experimental and control groups (Fig.6). 


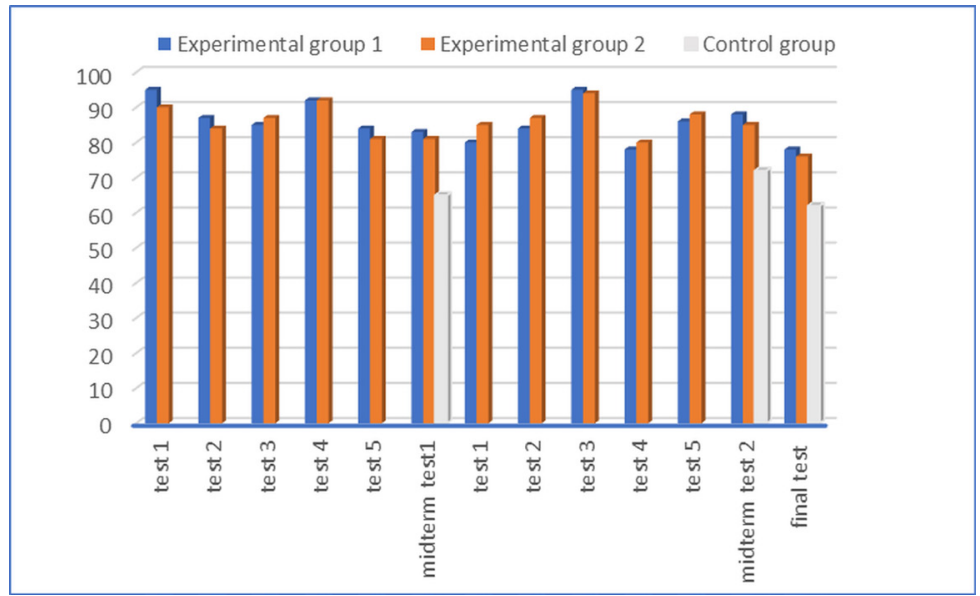

Fig. 6. The bar chart of the average test scores of the experimental and control groups.

We can see from the Fig.6 that the levels of professional vocabulary of all student groups experienced an upward trend throughout the academic year. They all had some fluctuations, but the levels of the experimental groups outraced the control group. We can note that the levels of professional vocabulary of the experimental groups was higher the level of the control group almost in two times at the end of the academic year. Thus, we can conclude that ESP lessons supported with digital educational tools could increase the level of professional vocabulary of students. Moreover, such high results can be interpreted also by an active post-task/test discussion and lesson design transformation.

During the experiment we always used frontal discussions as post-test activity. The teacher enhanced discussion of difficult questions of the vocabulary test, asked problematic questions, encouraging students to find right answers. This experiment showed that instant feedback of the applied digital educational tools and post-test discussions led to deeper vocabulary memorizing and language skills improvement.

Finally, to know students' attitude to digital educational tools implemented in ESP lessons we developed the online questionnaire of 10 questions. The questionnaire was created in Google forms service and the link was offered to students via student social network VKontakte. Overall, according to the questionnaire the experimental students showed a positive attitude to the conducted experiment and a great interest in the integrated educational tools. They reported about easiness to use the web services, grown interest in doing interactive tasks with automatic evaluation, post-test discussions for better material understanding and the midterm test preparation and readiness to continue to study in this format. Almost all students pointed out the motivating nature of this learning format.

\section{Conclusion}

The data indicate that mining engineering students need better and more effective ways of learning ESP and their teachers need to employ more effective teaching methods. To follow new higher educational standards demand, which makes ICT competence and digital skills the inherent part of education and integrating e-learning and web-services into teaching, we transformed mining engineering students' role from passive recipients to engaged disputers with help of their smartphones. Mining engineering students claimed this approach improved their overall satisfaction with ESP study because of an innovative way of interaction in classroom formats. 
Digital educational tools have considerable potential in educational process due to the characteristics such as deeper digestion of learning material, instant feedback from students which allows to trace their learning problems (weak points), automatic evaluation of students' responses. The above advantages of digital tools in combination with traditional training techniques increase students' motivation and satisfaction with ESP learning and open great opportunities for education. The best motivation for students is the future opportunity to communicate with foreign colleagues and read such highly rated journals as «Minerals», «Eurasia Mining», «Non-ferrous Metals», «CIS Iron \& Steel Review» and free weekly electronic newsletter «Ore \& Metals Weekly». Students can easily find out relevant information in the field of coal mining and metallurgy.

\section{Acknowledgements}

The reported study was funded by RFBR according to the research project № 19-01300805 .

\section{References}

1. O. Kulikova, Vocabulary learning strategies and beliefs about vocabulary learning: a study of beginning university students of Russian in the United States (University of Iowa, Iowa, 2015)

2. O. Greenwald, A. Resenchuk, T. Sergeychick, E3S Web Conf., 105, 04019 (2019)

3. A. Perevalova, E3S Web Conf., 41, 04030 (2018)

4. I. Gubanova, A. Shirokolobova, MATEC Web Conf., 297, 06002 (2019)

5. A. DeGani, G. Martin, G. Stead, F. Wade, E-learning Standards, 25:3, 181-185 (2010)

6. D. Nicol, D. Macfarlane-Dick, Studies in Higher Education, 31:2, 199-218 (2010)

7. T. Talmo, G. Sivertsen Korpås, M. Mellingsæter, E. Einum, Proceedings of the 5th International Conference of Education, Research and Innovation, 19:21, 4540-4545 (2012)

8. J. Cook, Mobile phones as mediating tools within augmented contexts for development, Education in the wild: contextual and location-based mobile learning in action (University of Nottingham, Nottingham 2010)

9. P. Driver, International Journal of Computer Assisted Language Learning and Teaching, 2:4, 23-37 (2012)

10. N. Tunyova, E3S Web Conf., 105, 04041 (2019) 